\title{
Transaneurysmal Repair of a Giant Calcified Submitral Left Ventricular Aneurysm
}

\author{
Sachin Sanagar ${ }^{1}$, MBBS, MS, MCH; Shantesh Kaushik ${ }^{1}$, MBBS, MS, MCH; Sanjeev Jadhav ${ }^{1}$, MBBS, MS, MCH; Saurabh \\ Tiwari², MBBS, MD; Rahul Gupta ${ }^{3}$, MBBS, MD, DM
}

DOI: $10.21470 / 1678-9741-2019-0113$

\begin{abstract}
Submitral left ventricular aneurysm is a rare cardiac pathology with very few cases reported in the literature. These are nonischemic aneurysms mostly reported from Africa. Patients with submitral aneurysm exhibit varied clinical manifestations.
\end{abstract}

We report a case of calcified submitral aneurysm and its successful surgical management through a transaneurysmal approach.

Keywords: Submitral Aneurysm. Calcified Aneurysm. Cardiac. Mitral Valve.

\begin{tabular}{ll}
\hline Abbreviations, acronyms \& symbols \\
\hline ECG $\quad=$ Electrocardiogram \\
SMA $\quad=$ Submitral aneurysm \\
\hline
\end{tabular}

\section{INTRODUCTION}

Submitral aneurysms have been described predominantly in African populations, although they have also been reported in mixed races and Caucasians ${ }^{[1]}$. Recent studies have revealed a congenital base of the submitral aneurysm as complex embryogenesis, causing weakness in the left submitral ventricular wall, although a genetic link has been suspected because of the racial predilection. The other suggested etiologies are infection and inflammation, such as tuberculosis, rheumatic endocarditis and Takayasu's arteritis ${ }^{[2]}$. Of the different possible surgical approaches, we successfully used a transaneurysmal approach.

\section{CASE REPORT}

A 53-year-old schizophrenic male presented with progressive worsening of dyspnea on exertion in the last 3 years, with worsening for 2 weeks. He was treated for heart failure 3 months earlier at another hospital. There was no history of trauma, rheumatic fever or tuberculosis. At clinical examination, heart rate was $96 \mathrm{bpm}$ and blood pressure was 112/74 mmHg. The apex was in the $6^{\text {th }}$ left intercostal space, $3 \mathrm{~cm}$ lateral to the midclavicular line. On auscultation, a mild S1 and a late apical systolic murmur grade 3/6 were present. The electrocardiogram (ECG) showed sinus rhythm. Chest roentgenogram showed calcified cystic lesion in the left hilar region (Figure 1A). Transthoracic echocardiography revealed a large submitral aneurysm of size $11 \times 8 \times 7 \mathrm{~cm}$ posterolateral to the left ventricle with a $1.2 \mathrm{~cm}$ neck. Left ventricular ejection fraction was 50\%, with mild mitral regurgitation without pulmonary hypertension. Cardiac computed tomography revealed an aneurysm size of $11.4 \times 11.1 \mathrm{~cm}$, occupying the inferior left paracardiac hemithorax (Figure 1B). The ECG-gated cardiac angiogram showed opacification with contrast through the small neck inferolateral
'Department of Cardiothoracic Surgery, Apollo Hospitals, Navi Mumbai, India. 2Department of Cardiac Anesthesia, Apollo Hospitals, Navi Mumbai, India.

${ }^{3}$ Department of Cardiology, Apollo Hospitals, Navi Mumbai, India.

This study was carried out at the Apollo Hospitals, Navi Mumbai, India.
Correspondence Address: Sachin Pralhad Sanagar (iD) https://orcid.org/0000-0001-8438-1135 Department of Cardiothoracic Surgery, Apollo Hospitals Sector 23 Uran Phata, CBD Belapur, Navi Mumbai, Maharashtra, India Zip code: 400614

E-mail: sachin.sanagar@gmail.com; drsachin_s@apollohospitals.com 


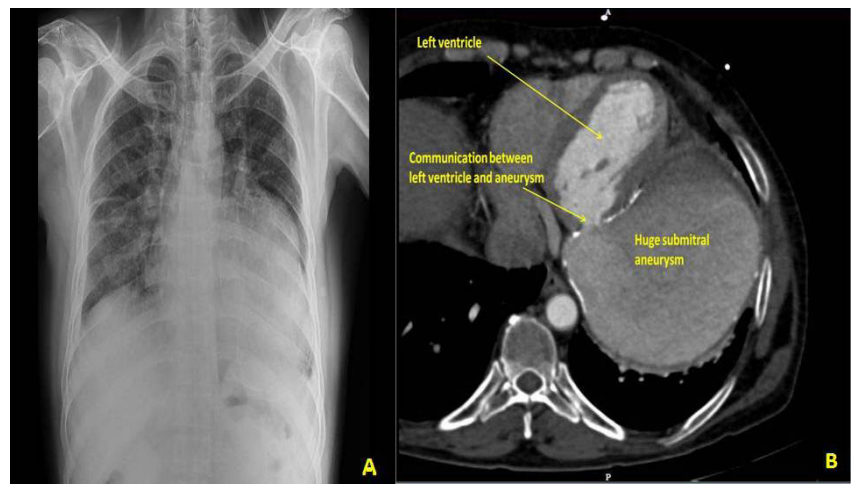

Fig. 1 - (A) Chest roentgenogram showing calcified cystic lesion in the left hilar region; (B) Computed tomography showing communication between left ventricle and submitral aneurysm.

to the mitral valve. The aneurysm wall was 3-5 mm thick with curvilinear calcification. Coronary angiography showed normal coronary arteries. Left ventriculography confirmed the contrast flow from the left ventricle to the aneurysm. The aneurysm was just abutting the obtuse marginal branch of the left circumflex coronary artery. Open repair of the aneurysm through a midline sternotomy was planned. Cardiopulmonary bypass with aortobicaval cannulation and cardioplegic arrest allowed dissection of the aneurysm. The left ventricular aneurysm arising from the posterior submitral region was opened and its contents evacuated (Figure 2). The free aneurysmal calcified wall was partially excised, keeping the lateral part adherent to the hilum, in situ. On inspection, mitral subvalvar apparatus was intact. The defect was repaired with a bovine pericardial patch using the 2-0 Prolene continuous suture technique. Free aneurysmal wall

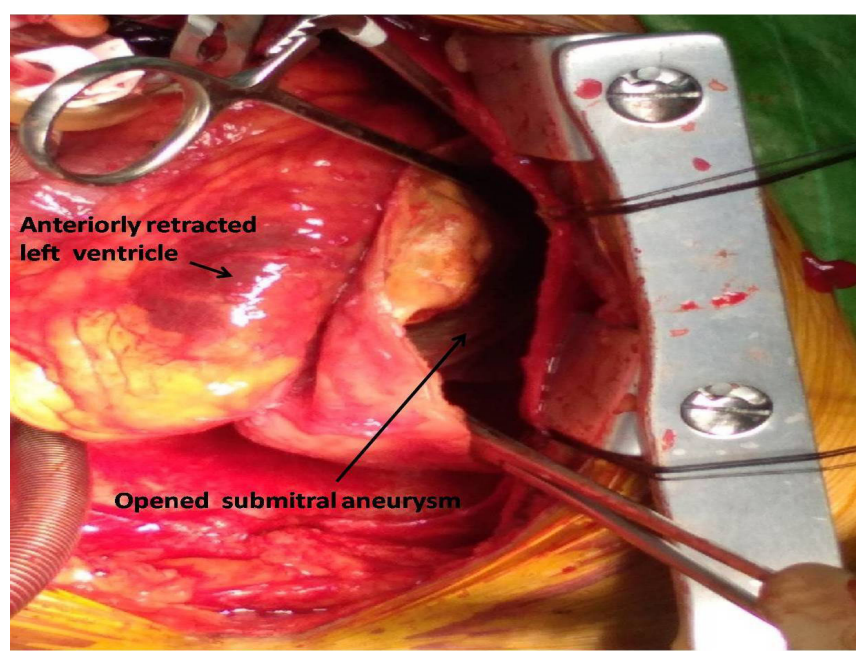

Fig. 2 - Opened submitral aneurysm. margins were sutured over the pericardial patch. Intraoperative transesophageal echocardiography confirmed complete repair without leakage. The patient was extubated after 10 hours. Postoperatively, his schizophrenic symptoms worsened, for which he received treatment and responded well, and was discharged on the $11^{\text {th }}$ postoperative day. Histopathological examination of the aneurysmal wall showed bands of dense eosinophilic tissue, areas of fibroid necrosis, hemorrhage and foci of calcification.

Doppler echocardiography after one month showed good left ventricular function with mild mitral regurgitation.

\section{DISCUSSION}

Most submitral aneurysms (SMAs) are reported in Africa, with the first case reported in 1962 by Abrahams et al. ${ }^{[3]}$. Recently, few cases have been reported in the Indian subcontinent ${ }^{[4]}$. Clinically, submitral aneurysms are characterized by heart failure, mitral insufficiency, and absence of coronary disease associated with thromboembolic cardiomyopathy and cardiac arrhythmias $^{[5]}$. Compression of coronary arteries by the aneurysm can have ischemic manifestations. Transthoracic Doppler is usually diagnostic. Aneurysm details such as neck size and extension can be accurately defined with the help of magnetic resonance imaging. Contrast-enhanced computed tomography angiography reveals the SMA calcification and compression of the adjacent structures. The aneurysm neck closure with bovine pericardium is the treatment of choice. Either sternotomy or left thoracotomy approach can be used. Aneurysm neck can be accessed through transmitral, left atrial or transaneurysmal route ${ }^{[4,6]}$. Closing the aneurysm wall over the patch ensured good hemostasis and reduced the chances of patch aneurysm formation.

\section{CONCLUSION}

Submitral left ventricular aneurysm is a rare entity. In our case, transaneurysmal approach was adopted, as the need for mitral intervention was unlikely. Definitive diagnosis with thorough preoperative evaluation and good surgical technique lead to successful surgical outcomes for submitral aneurysms.

\section{ACKNOWLEDGMENTS}

The authors would like to thank to Dr. Akhilesh Tandelkar and Dr. Gunadar Padhi, intensivists involved in postoperative care, and to Mr. Bony Thomas, physician assistant.

\section{No financial support. No conflict of interest.}




\section{Authors' roles \& responsibilities}

SS

Substantial contributions to the conception or design of the work; or the acquisition, analysis, or interpretation of data for the work; drafting the work or revising it critically for important intellectual content; final approval of the version to be published

SK

Substantial contributions to the conception or design of the work; or the acquisition, analysis, or interpretation of data for the work; drafting the work or revising it critically for important intellectual content; final approval of the version to be published

SJ Substantial contributions to the conception or design of the work; or the acquisition, analysis, or interpretation of data for the work; final approval of the version to be published

ST Substantial contributions to the conception or design of the work; or the acquisition, analysis, or interpretation of data for the work; final approval of the version to be published

RG Substantial contributions to the conception or design of the work; or the acquisition, analysis, or interpretation of data for the work; final approval of the version to be published

\section{REFERENCES}

1. Sinha SK, Verma CM, Thakur R, Kumar V, Sachan M, Kumar A, et al. Subvalvar mitral aneurysm: a rare cause of mitral leak. Cardiol Res. 2015;6(3):297-9. doi:10.14740/cr408w.

2. Baruah DK, Kumar PV, Reddy GS, Babu VR. Submitral aneurysm of the left ventricle. Indian Heart J. 2012;64(1):77-9. doi:10.1016/S00194832(12)60015-7.

3. Abrahams DG, Barton CJ, Cockshott WP, Edington GM, Weaver CJ. Annular subvalvular left ventricular aneurysms. Q J Med. 1962;31:345-60.

4. Rajbanshi BG, Rajbhandari N, Pradhan S, Karki A, Gyawali P, Sharma M, et al. Submitral aneurysm: an unusual aneurysm of the left ventricle. Ann Thorac Surg. 2019;108(1):e11-3. doi:10.1016/j.athoracsur.2018.10.073.

5. Skoularigis J, Sareli P. Submitral left ventricular aneurysm compressing the left main coronary artery. Cathet Cardiovasc Diagn. 1997;40(2):173-5. doi:10.1002/(sici)1097-0304(199702)40:2<173:.aid-ccd12>3.0.co;2-s.

6. Purushotham S, Manohar SR, Sivasubramaniam S, Neelakandhan KS. Submitral left ventricular aneurysm: the location of the circumflex coronary artery in relation to the aneurysm influences the surgical approach and outcome. JThorac Cardiovasc Surg. 2005;129(5):1175-7. doi:10.1016/j.jtcvs.2004.08.044 